\title{
Microcrystalline structure and quasi-crystal formation in rapidly quenched (AI-Ti)-(Fe, Mn) alloys
}

\author{
A.R. Yavari and J.-L. Verger-Gaugry \\ LTPCM/ENSEEG/INPG (CNRS UA 29), BP 75, Domaine Universitaire, 38402 Saint \\ Martin d'Hères, France
}

\begin{abstract}
We have performed an X-ray diffraction study of several microcrystalline binary and ternary alloys of the ( $\mathrm{Al}-\mathrm{Ti})-(\mathrm{Mn}-\mathrm{Fe}-\mathrm{Ni}$ ) system prepared by melt-spinning. The results indicate that while $\mathrm{Ti}_{2} \mathrm{Ni}$ is fully amorphous, $\mathrm{Ti}_{2} \mathrm{Fe}$ forms metastable crystalline phase(s) with little or no i-phase fractions. The spectra of microcrystalline binary Ti-Mn alloys present similarities to that of the i-phase. Ternary (AlTi) ${ }_{1-x} \mathrm{Fe}_{x}(\mathrm{AlTi})_{1-x} \mathrm{Mn}_{x}$ are found to be isostructural near $\mathrm{x}=30$ at $\%$ but seem not to contain significant i-phase while the ternary Al-rich $\mathrm{Al}_{72} \mathrm{Ti}_{10} \mathrm{Mn}_{18}$ seems to be partially quasi-crystalline (QC). Electron diffraction patterns obtained for binary $\mathrm{Ti}_{56} \mathrm{Mn}_{44}$ whose X-ray spectrum resembles that of the i-phase show spots with five-fold sym- metry together with a periodic lattice and a lot of streaking.
\end{abstract}




\section{Introduction}

Since the first observations of metastable phases with icosahedral symmetry in rapidly quenched $\mathrm{Al}-$ Mn alloys [1, 2], many such observations have been reported in other binary and ternary alloys [3]. Evidence concerning phases with icosahedral symmetry in these alloys have been mostly obtained by selected-area electron diffraction from regions constituting unspecified volume fractions of the samples although in some cases nearly $100 \%$ icosahedral phase formation has been achieved. In such cases, X-ray diffraction patterns show no other major peaks than those attributed to the icosahedral quasi-crystalline structure [4]. Near $100 \%$ icosahedral phase content has been achieved and reported here and elsewhere [3] in $\mathrm{Al}_{80} \mathrm{Mn}_{20}, \mathrm{Al}_{78} \mathrm{Re}_{22}$ [5] prepared by rapid quenching, in an $\mathrm{AlMgZn}$ alloy [6] prepared both by rapid quenching and solid-state reaction and in $\mathrm{Pd}-\mathrm{U}-\mathrm{Si}$ [7] obtained by annealing of the melt-spun amorphous alloy. Models [8-10] have been proposed for the atomic structures that reproduce the symmetry of the observed diffraction patterns and detailed decorations of the model bone structures are subject of current debate.

It has also been reported that icosahedral quasicrystals form in $\mathrm{Ti}_{2} \mathrm{Ni}$ [11] and $\mathrm{Ti}_{2} \mathrm{Fe}$ [12] and in Al-rich, Al-Ni and Al-Fe [13]. Furthermore for reasons that will be published elsewhere [14] we expected quasi-crystal formation in rapidly quenched Ti-Mn alloys. We therefore decided to prepare binary $\mathrm{Ti}-\mathrm{Mn}, \mathrm{Ti}-\mathrm{Ni}$ and $\mathrm{Ti}-\mathrm{Fe}$ alloys by melt-spinning and compare the X-ray diffraction spectra to those of known QC (icosahedral (i) and decagonal (T)) phases in $\mathrm{Al}-\mathrm{Mn}$. In view of the reported QC formation tendency in the $\mathrm{Al}$-rich and $\mathrm{Ti}$-rich alloys and since $\mathrm{Al}$ and $\mathrm{Ti}$ have nearly equal atomic radii, we also explored ternary ( $\mathrm{Al}-\mathrm{Ti})-\mathrm{Fe}$ and $(\mathrm{Al}-\mathrm{Ti})-\mathrm{Mn}$ microcrystalline alloys.

\section{Experimental procedure}

The alloys were prepared by levitation melting of the constituents and melt-spun in quartz crucibles under helium gas using various substrate rotation velocities. $\mathrm{X}$-ray diffraction spectra were obtained using $\mathrm{Cu} K \alpha$ radiation. Melt-spun ribbons were ion thinned at liquid $\mathrm{N}_{2}$ temperature using $4 \mathrm{keV}$ argon ions. Transmission electron microscopy (TEM) was performed in a JEOL 200-CX microscope and determination of the stoichiometry of phases was achieved by X-EDS in a vacuum generator-HB 501 scanning transmission electron microscope allowing spot sizes down to less than $0.8 \mathrm{~nm}$ and equipped with a field emission gun.

\section{Results and discussion}

\subsection{X-ray diffraction}

Since we are mainly interested here in microcrystalline alloys with important volume fractions of quasi crystalline phases, we begin with an examination of X-ray diffraction patterns of each sample. Fig. 1 shows $\mathrm{X}$-ray diffraction spectra of rapidly quenched $\mathrm{Ti}_{2} \mathrm{Ni}$ and $\mathrm{Ti}_{2} \mathrm{Fe}$ in which QC formation has been reported $[11,12]$ and of $\mathrm{Ti}_{56} \mathrm{Mn}_{44}$. Also shown for comparison in Fig. 1 are the spectra of $\mathrm{Al}_{80} \mathrm{Mn}_{20}$ and $\mathrm{Al}_{77.5} \mathrm{Mn}_{22.5}$ obtained at substrate velocities of 65 and $50 \mathrm{~m} \mathrm{sec}^{-1}$ to favour formation of the i-phase and $30 \mathrm{~m} \mathrm{sec}^{-1}$ for the T-phase [3]. It can be seen that $\mathrm{Ti}_{2} \mathrm{Ni}$ is amorphous while the Bragg peaks of $\mathrm{Ti}_{2} \mathrm{Fe}$ are not typical of either the $\mathrm{i}$ - or the $\mathrm{T}$-phase. Observations of the $\mathrm{i}$-phase by TEM in these rapidly quenched alloys as reported in references [11] and [12] must have therefore been limited to a very small volume-fraction of the samples. However the Ti-Mn spectra and particularly that of 


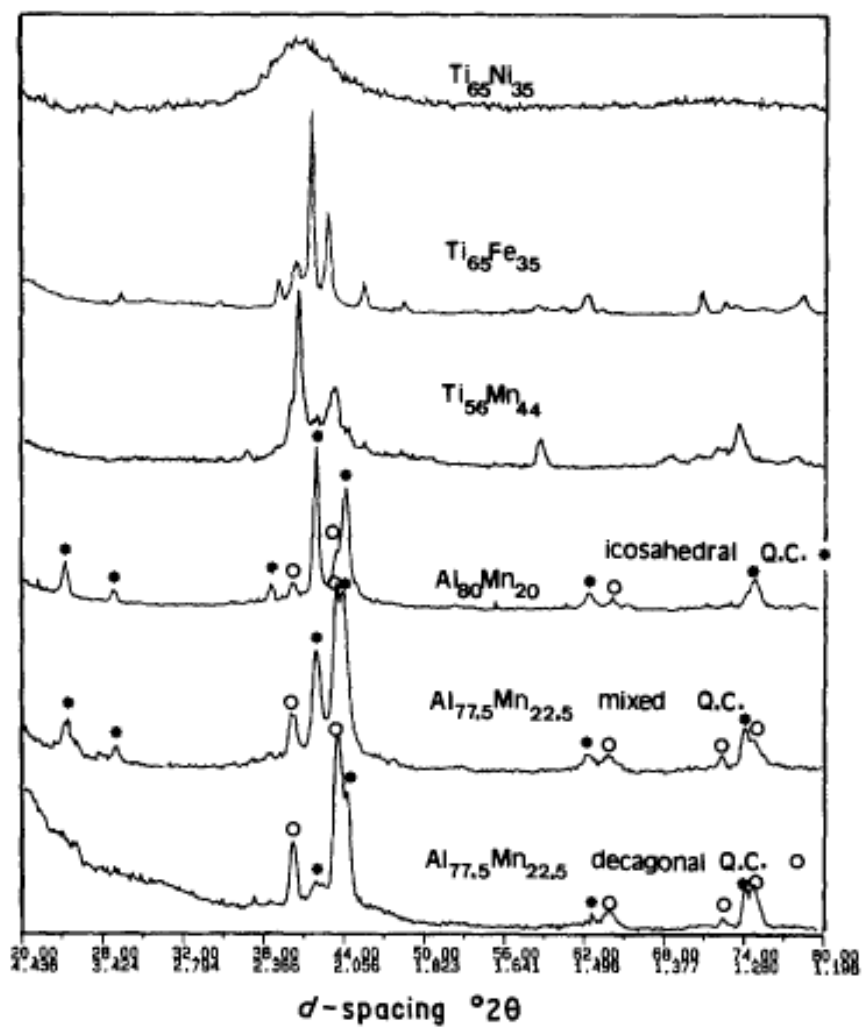

Figure I X-ray diffraction patterns of rapidly quenched $\mathrm{Al}_{7.5}, \mathrm{Mn}_{22.5}, \mathrm{Al}_{80} \mathrm{Mn}_{20}, \mathrm{Ti}_{56} \mathrm{Mn}_{44}, \mathrm{Ti}_{65} \mathrm{Fe}_{35}, \mathrm{Ti}_{65} \mathrm{Ni}_{35}$.

the $\mathrm{Ti}_{56} \mathrm{Mn}_{44}$ alloy as presented here show some broad resemblence to that of icosahedral $\mathrm{Al}_{80} \mathrm{Mn}_{20}$ with a notable absence of the low angle peaks which have been known to disappear in neutron diffraction spectra of Al-Mn-Cr QC alloys [15]. Table I lists the values of $Q=4 \pi \sin \theta / \lambda$ (with $\lambda=0.154 \mathrm{~nm}$ ) corresponding to the Bragg peaks of the i-phase in the $\mathrm{Al}_{80} \mathrm{Mn}_{20}$ spectrum of Fig. 1 together with $Q$-values from the precision measurements of Bancel et al. [4] for the $i$-phase in $\mathrm{Al}_{86} \mathrm{Mn}_{14}$. The peaks are attributed to various planes of the i-phase quasi-lattice using the notation of Bancel et al. [4]. Also shown are all the peaks appearing in the $\mathrm{Ti}-\mathrm{Mn}$ alloy spectrum. The positions of various peaks in reciprocal space are compared using the ratio $Q / Q^{*}$ where $Q^{*}$ is the chosen fundamental lattice vector corresponding to the (100000) plane. This normalization removes differences due to scale changes and the reciprocal lattice constant $Q_{0}$ [4] corresponding to differences in real space quasi-lattice constants. It is seen that all the Ti-Mn alloy peak positions can be fitted to those of an Al-Mn type i-phase with an error ranging from 0 to $2 \%$. The difference in the $Q$-values indicates that the unit scale of the reciprocal lattice in $\mathrm{Ti}-\mathrm{Mn}$ would be $\sim 3 \%$ smaller and the rhombohedral edge length $\sim 3 \%$ larger. However with the low-angle peaks being absent in the Ti-Mn spectrum, such an identification is based on five peaks only. We therefore decided to study the $\mathrm{Ti}_{56} \mathrm{Mn}_{44}$ alloy by TEM and found a periodic structure which seems to be related to the non-periodic i-phase (see Section 3.2.). Fig. 2 shows X-ray diffraction spectra for rapidly quenched ternary $\mathrm{Al}_{72} \mathrm{Ti}_{10} \mathrm{Mn}_{18}$, (AlTi) ${ }_{65} \mathrm{Mn}_{35}$, (AlTi) ${ }_{67} \mathrm{Fe}_{33}$ and (AlTi) ${ }_{73} \mathrm{Fe}_{27}$. Also shown again is the $\mathrm{Al}_{80} \mathrm{Mn}_{20}$ spectrum for comparison. Although none of the ternary alloys present an i-phase like spectrum, Fig. 2 shows that some of the peaks of

TABLE 1 Comparison of Bragg peaks ( $Q$-values) of $\mathrm{Ti}_{56} \mathrm{Mn}_{44}$ and $\mathrm{Al}_{72} \mathrm{Ti}_{10} \mathrm{Mn}_{18}$ with those of $\mathrm{Al}_{82} \mathrm{Mn}_{20}$ i-phase

\begin{tabular}{|c|c|c|c|c|c|c|c|c|}
\hline \multirow[t]{2}{*}{$\begin{array}{l}\text { i-phase } \\
\text { plane }\end{array}$} & \multicolumn{2}{|c|}{$\begin{array}{l}\text { i-phase in } \mathrm{Al}_{6} \mathrm{Mn} \\
\text { (Bancel } \text { et al. }[4 \mathrm{]})\end{array}$} & \multicolumn{2}{|c|}{$\begin{array}{l}\text { i-phase in } \mathrm{Al}_{30} \mathrm{Mn}_{20} \\
\text { (this work) }\end{array}$} & \multicolumn{2}{|c|}{ microcryst. $\mathrm{Ti}_{56} \mathrm{Mn}_{44}$} & \multicolumn{2}{|c|}{ microcrys. $\mathrm{Al}_{22} \mathrm{Ti}_{10} \mathrm{Mn}_{18}{ }^{\dagger}$} \\
\hline & $Q\left(\mathrm{~nm}^{-1}\right)$ & $Q / Q^{*}$ & $Q\left(\mathrm{~nm}^{-1}\right)$ & $Q / Q^{*}$ & $Q\left(\mathrm{~nm}^{-1}\right)$ & $Q / Q^{*}$ & $Q\left(\mathrm{~nm}^{-1}\right)$ & $Q / Q^{*}$ \\
\hline 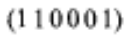 & 0.163 & 0.056 & 0.165 & 0.056 & - & - & 0.161 & 0.055 \\
\hline 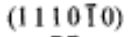 & 0.188 & 0.065 & 0.190 & 0.065 & - & - & 0.182 & 0.064 \\
\hline $\begin{array}{l}(21 \text { I I } 01) \\
\left(Q^{*}\right)\end{array}$ & 0.264 & 0.091 & 0.270 & 0.092 & 0.258 & 0.091 & 0.268 & 0.092 \\
\hline $\begin{array}{l}(100000) \\
\text { (5-fold) }\end{array}$ & $Q^{*}=0.290$ & 0.100 & $Q^{*}=0.292$ & 0.100 & $Q^{*}=0.283$ & 0.100 & $Q^{*}=0.291$ & 0.100 \\
\hline $\begin{array}{l}(110000) \\
\text { (2-fold) }\end{array}$ & 0.304 & 0.105 & 0.306 & 0.105 & 0.300 & 0.106 & 0.305 & 0.105 \\
\hline 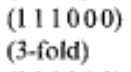 & 0.420 & 0.145 & 0.422 & 0.144 & 0.400 & 0.142 & - & - \\
\hline 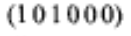 & 0.493 & 0.170 & 0.494 & 0.169 & 0.487 & 0.172 & - & - \\
\hline
\end{tabular}

$Q=4 \pi \sin \theta / \lambda$, see $2 \theta$ values of Figs 1 and $2(\lambda=0.154 \mathrm{~nm})$.

†For $\mathrm{Al}_{32} \mathrm{Ti}_{10} \mathrm{Mn}_{13}$, only peaks at $2 \theta$ angles near those of the AlMn i-phase have been indexed. The other peaks in this spectrum do not fit those of $\mathrm{fcc} \mathrm{Al}$ and have not been identified. 


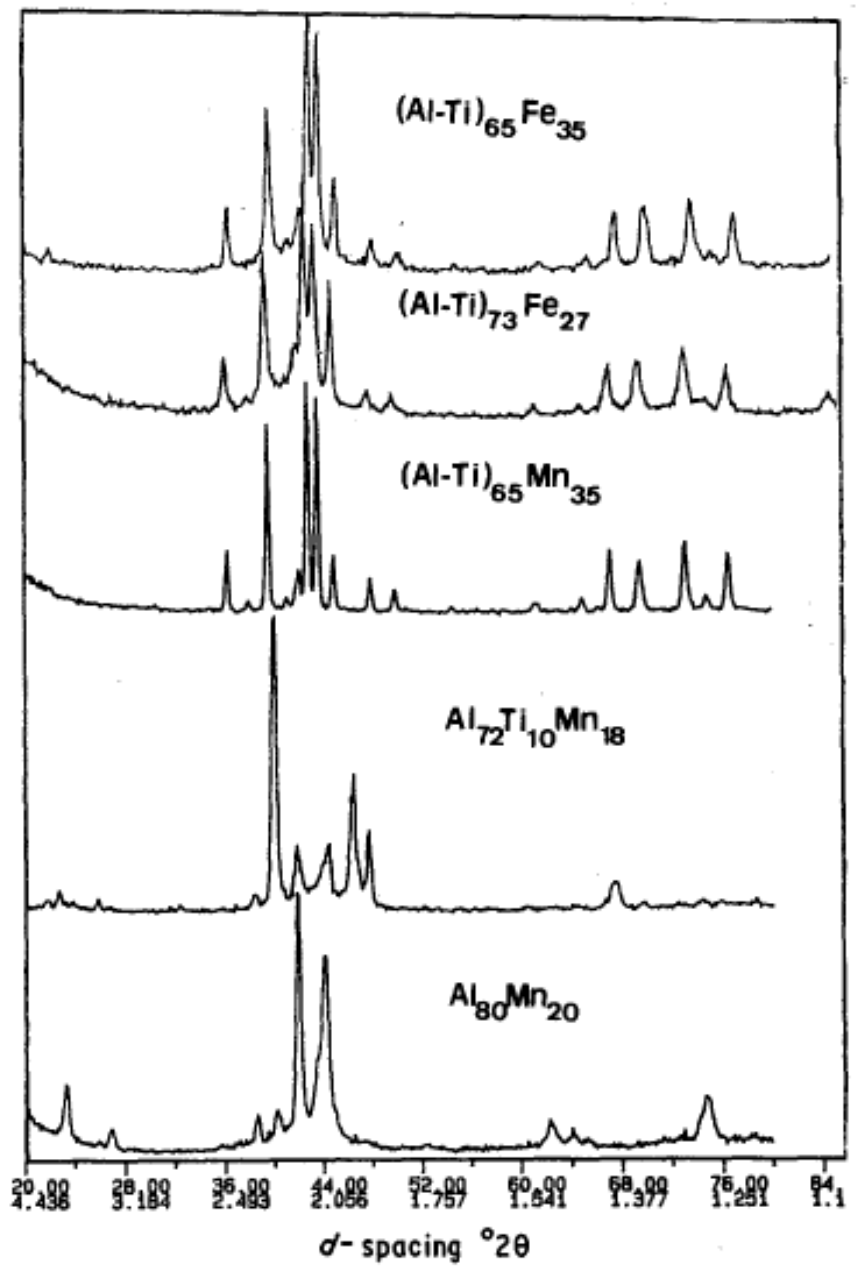

Figure $2 \mathrm{X}$-ray diffraction in ternary microcrystalline $(\mathrm{Al}-\mathrm{Ti})_{67} \mathrm{Fe}_{33},(\mathrm{Al}-\mathrm{Ti})_{73} \mathrm{Fe}_{27},(\mathrm{Al}-\mathrm{Ti})_{69} \mathrm{Mn}_{35}, \mathrm{AL}_{72} \mathrm{Ti}_{10} \mathrm{Mn}_{18}$ (and $\mathrm{Al}_{p 0} \mathrm{Mn}_{20}$ for comparison).

$\mathrm{Al}_{72} \mathrm{Ti}_{10} \mathrm{Mn}_{18}$ occur at the same angles as those of the i-phase. Table I compares $Q$-values corresponding to these peaks to those of the Al-Mn i-phase. Although the low intensity high-angle peaks are absent, the $Q$-values normalized (divided) by the fundamental $Q^{*}$ of the $(100000)$ planes correspond to those of the $\mathrm{i}$-phase in binary Al-Mn to within about $2 \%$. It is in fact not surprising that $\mathrm{i}$-phase QCs appear in this ternary alloy as it corresponds to $\mathrm{Al}_{80} \mathrm{Mn}_{20}$ with about $15 \%$ of the $\mathrm{Al}$ atoms replaced by $\mathrm{Ti}$. Another interesting finding reported here for the first time is that the microcrystalline (AlTi) ${ }_{67} \mathrm{Fe}_{33}$, (AITi) ${ }_{73} \mathrm{Fe}_{27}$ and $(\mathrm{AlTi})_{65} \mathrm{Mn}_{35}{ }^{*}$ produce peaks of identical symmetry indicating that their crystal structure(s) are identical (Fig. 2). This was unexpected since $\mathrm{Ti}_{2} \mathrm{Fe}$ (Fig. 1) and $\mathrm{Ti}_{2} \mathrm{Mn}$ with a spectrum (not shown) similar to that of $\mathrm{Ti}_{56} \mathrm{Mn}_{44}$ (Fig. 1) are clearly very different and so are those of $\mathrm{Al}_{80} \mathrm{Mn}_{20}$ and $\mathrm{Ti}_{80} \mathrm{Mn}_{20}$ [14]. The ternary $(\mathrm{AlTi})_{1-x} \mathrm{M}_{x}$ alloys are interesting for neutron studies if $\mathrm{Al}$ and $\mathrm{Ti}$ which have near equal atomic volumes occupy equivalent sites in which case their average neutron coherent scattering length $\bar{b}=\left(b_{\mathrm{Ti}}+b_{\mathrm{Al}}\right) / 2=0$ because $b_{\mathrm{Ti}}$ is negative and $\left|b_{\mathrm{Ti}}\right|=b_{\mathrm{A} 1}=0.35 \times 10^{-12} \mathrm{~cm}$. Furthermore, some alloys such as $(\mathrm{AlTi})_{1-x}\left(\mathrm{Fe}_{27} \mathrm{Mn}_{73}\right)_{x}$ (with $b_{\mathrm{Mn}}$ and $b_{\mathrm{Fe}}$ equal to -0.36 and $0.96 \times 10^{-12} \mathrm{~cm}$ respectively) will be isostructural zero-alloys if they are single-phased, thus producing no neutron scattering at all.

\subsection{TEM observations on microcrystalline $\mathrm{Ti}_{56} \mathrm{Mn}_{44}$}

Several phases can be observed in $\mathrm{Ti}_{56} \mathrm{Mn}_{44}$ samples even though X-ray diffraction produces only a small number of peaks thus suggesting that the ribbons may

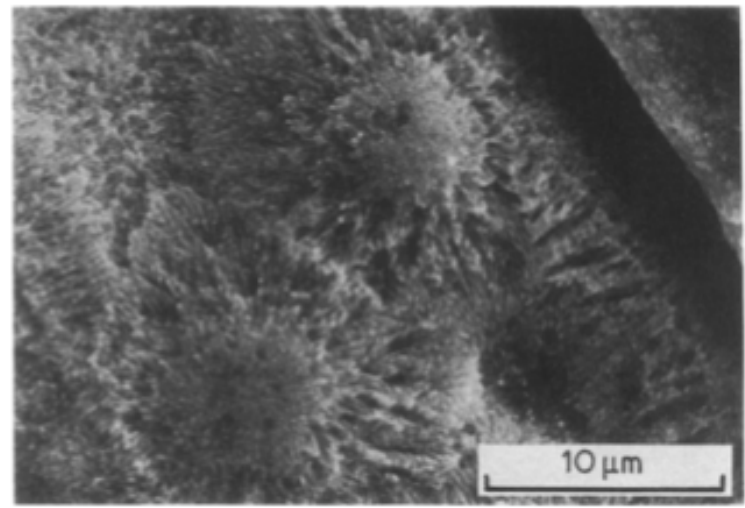

Figure 3 Wheel side of $\mathrm{Ti}_{96} \mathrm{Mn}_{44}$ melt-spun ribbon etched in $\mathrm{HF}$ : dendritic growth of particles.

*The diffraction patterns of (AITi) ${ }_{65} \mathrm{Ti}_{35}$, (AlTi $)_{73} \mathrm{Fe}_{27}$ and (AITi) ${ }_{65} \mathrm{Mn}_{35}$ (Fig. 2) have now been fully indexed and correspond to a single-phase $\mathrm{Mn}_{2}$ Ti type Laves phase whose phase field can thus be extended by rapid solidification as will be discussed further elsewhere [14]. 

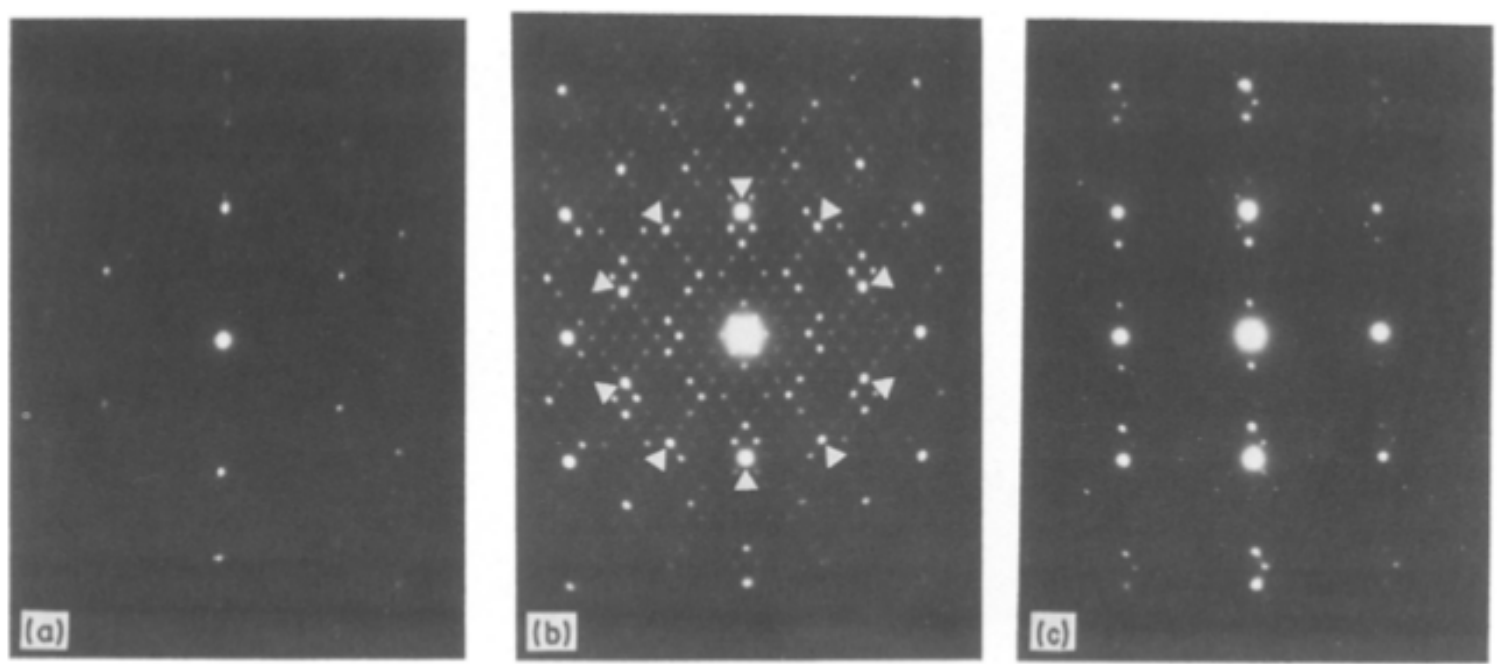

Figure 4 Selected area electron diffraction patterns of $\mathrm{Ti}_{56} \mathrm{Mn}_{44}$ showing (a) three-fold symmetry and a lot of streaking: (b) periodic pattern containing spots with ten- or five-fold symmetry (white arrows indicate one such set); (c) two-fold symmetry relative to a bcc lattice.

contain essentially only one phase. Particle size is generally below $1 \mu \mathrm{m}$ and may arise from large dendrites which have grown from the wheel side (Fig. 3) and have been cut during thin foil preparation. Even if these particles are not connected, they possess almost the same orientation in some regions. The electron diffraction patterns (EDP) of these particles often reveal a lot of streaking similar to that found in the decagonal T-phase [16] (Fig. 4a). The identification of the phases present, all of which appear to be periodic, is still in progress. They include the low symmetry phase resulting in the EDP pattern of Fig. $4 \mathrm{~b}$ and a bcc phase with lattice parameter $a=0.35 \mathrm{~nm}$. Interestingly, some of the more intense reflections of the periodic pattern in the EDP of Fig. 4b follow a near ten- or five-fold rotational symmetry (see white arrows) with an inflation factor varying from 0.145 to 0.175 instead of $=0.1618$ (or $\tau^{3}$ ) in the i-phase (other concentric rings of such spots can be found in Fig. $4 \mathrm{~b}$ but have not been marked-out). A similar superposition of spots with ten-fold rotational symmetry on another periodic EDP was reported by Kuo et al. in a VNiSi alloy [17]. The common features, both in the X-ray pattern and the EDP of the periodic $\mathrm{Ti}_{56} \mathrm{Mn}_{44}$ phase (called here the V-phase) for which no references exist so far in the literature, and the icosahedral phase is relevant since the periodic arrangement of the V-phase, as in AlFeSi [9] for the $\alpha$-phase for instance, allows a periodic description approximating the quasi-lattice atomic decoration of the $\mathrm{i}$-phase. In the $\mathrm{Ti}_{56} \mathrm{Mn}_{44}$ sample, this phase appears to be in a very fine-scale eutectic structure with the b c c phase. A more precise description of these phases and their compositions will be given elsewhere [14, 18].

\section{Acknowledgements}

Thanks are due to Dr M. Audier for very helpful discussions and to Dr Bochu for the acquisition of the X-ray patterns.

\section{References}

1. D. SHECHTMAN, I, BLECH, D. GRATIAS and J, W, CAHN, Phys. Rev. Lett. 53 (1984) 1951.

2. R. D, FIELD and H, L. FrASER, Mat. Sci. Eng, 68 (1984-85) 417,

3. R. J. SCHAEFER, Scripta Met. 20 (1986) 1187.

4. P. A. BANCEL, P. A. HEINEY, P. N. STEPHENS, A. I. GOLDMAN and P. M. HORN, Phys, Rev, Lett, 54 (1985) 2422.

5. P. A. BANCEL and P. A. HEINEY, J. de Physique 47 (1986) C3-341.

6. W. A. CASSADA, Y. SHEN, S. J. POON and G. SHIFLET, Phys. Rev. B. 34 (1986) 7413.

7. S. J. POON, A. J. DREHMAN and K. R. LAWLESS, Phys. Rev. Lett. 55 (1985) 2324.

8. L. PAULING, Nature 317 (1985) 512.

9. P. GUYOT and M. AUdier, Phil. Mag. B 52 (1985) L15.

10. M. J. CARR, J. Appl. Phys. 59 (1986) 1063.

11. Z. ZHANG, H, Q. YE and K. H. KUO, Phil. Mag. A 52 (1985) LA9.

12. C. DONG, Z. K. HEI, L. B. WANG, Q. H. SONG, Y. K. WU and K. H. KUO, Scripta Met. 20 (1986) 1155.

13. R. A. DUNLAP and K. DINI, J. Phys, F, 16 (1986) 11.

14. A. R. YAVARI, to be published.

15. R. BELLISSENT, F. BOUREE-VIGNERON and P. SAINFORT, J. de Physique 47 (1986) C3-361,

16. K. H. KUO, D. S. ZHOU and D. X. LI, Phil. Mag. Leth. 55 (1987) 33.

17. L. BENDERSKY, Phys, Rev, Lett, 55 (1985) 1461.

18. J,-L. VERGER-GAUGRY, et al., in preparation. 